\title{
Análise ambiental do processo turístico da segunda residência e suas
} implicações

Environmental analysis of the process tourism of second residence and its implications

Análisis ambiental del proceso turístico de la vivienda secundaria y sus implicaciones

Lucivan Macena de Carvalho

Turismólogo UFPE, Brasil lucivan.macena@ufpe.br

Emerson Luis Tonetti Professor Doutor, IFPR, Brasil. emerson.tonetti@ifpr.edu.br

Everaldo dos Santos Professor Doutor, IFPR, Brasil. everaldo.santos@ifpr.edu.br 
A atividade turística de modo geral é considerada um fenômeno de nível internacional e por essa razão tem sido motivo de vários estudos. Dentre os segmentos diversos, a segunda residência, é um tema ainda pouco estudado pelo setor acadêmico, mas que de modo geral, abrange os setores econômicos, culturais, sociais e ambientais. Essa segmentação turística requer uma atenção especial devido à ausência no Brasil de estudos mais aprofundados e suas possíveis implicações. O presente artigo resulta de uma pesquisa teórica e empírica, sendo seu objetivo principal evidenciar o aumento do consumo gerado pelo turismo de segunda residência no balneário Ipanema, no litoral do estado do Paraná. Com este objetivo foi levantado a distribuição do uso do solo em residencial permanente e ocasional, comercial permanente e ocasional, elaborar um croqui com essa distribuição e feito inferências a partir da literatura que discutem os problemas ambientais decorrentes da sazonalidade do turismo no balneário Ipanema, no município de Pontal do Paraná. Dentre os principais resultados encontrados na pesquisa está a distribuição dos domicílios ocasionais e permanentes posicionados praticamente de forma opostas, o aumento no consumo de energia elétrica, água, efluentes e resíduos sólidos na alta temporada. Tais resultados evidenciam a elevação do consumo sazonal e a potencial sobrecarga ambiental que sofre o balneário em estudo, acarretando em transtornos para a população local.

PALAVRAS-CHAVE: segunda residência; turismo e meio ambiente; balneário Ipanema.

\section{ABSTRACT}

Tourist activity in General is considered a phenomenon of international level and for this reason has been cause for various studies. Among the various segments, the second residence, is a subject still little studied by the academic sector, but that in General, covering the economic, cultural, social sectors and environmental. This tourist segmentation requires special attention due to the absence in Brazil of more detailed studies and its possible implications. This article is the result of theoretical and empirical research, being your main objective to highlight the increased consumption generated by tourism of second residence in the Ipanema beach, on the coast of the State of Paraná. With this objective, the distribution of land use was collected in a permanent and occasional, permanent and occasional commercial service, with a sketch with a distribution and made inferences for a series of questions about the nature of tourism in the Ipanema beach, in the municipality of Pontal of Paraná. The results found in the research are the distribution of occasional and permanent domiciliary data in practically opposite positions, the increase in electricity consumption, water, effluents and solid waste in high season. This is a process of analysis of potential seasonal and potential environmental overload that involves the development of a study on eating disorders for a local population.

KEYWORDS: second residence; tourism and the environment; Ipanema beach resort.

\section{RESUMEN}

El turismo de manera generalizada es un fenómeno de nivel internacional y por eso ha sido estudiado a lo largo de los años, pero dentro de los segmentos tan distintos, la vivienda secundaria, algo todavía no aclarado por la academia, pero tan importante al paso de que tiene que ver con los sectores económicos, culturales, sociales y ambientales, los dos últimos temas serán estudiados en profundidad en las próximas páginas. Es una segmentación que necesita una atención por la falta de pesquisas mas detalladas en Brasil, además de sus implicaciones. El presente artículo de investigación tiene su principal objetivo destacar el incremento del consumo generado por el turismo de la vivienda secundaria en balneario Ipanema, ubicado en la costanera de Paraná. Con este objetivo se levantó la distribución del uso del suelo en residencial permanente y ocasional, comercial permanente y ocasional, elaborar un croquis con esa distribución e hecho inferencias a partir de la literatura que discuten los problemas ambientales derivados de la estacionalidad del turismo en el balneario Ipanema, en el municipio de Pontal do Paraná. Entre los principales resultados encontrados en la investigación está la distribución de los domicilios ocasionales y permanentes posicionados prácticamente de forma opuesta, el aumento en el consumo de energía eléctrica, agua, efluentes y residuos sólidos en la alta temporada. Tales resultados evidencian la elevación del consumo estacional y la potencial sobrecarga ambiental que sufre el balneario en estudio, acarreando en trastornos para la población local.

PALABRA CLAVE: Vivenda secundaria; turismo y medio ambiente; balneario Ipanema. 


\section{INTRODUÇÃO}

O turismo de segunda residência é apenas uma das mais variadas segmentações da atividade turística a nível mundial e que envolve o uso residencial próprio ou locado, além de atividades de lazer baseados nas regiões costeiras ou rurais, Assis (2003). A segunda residência ou residência secundária é um tipo de hospedagem vinculada a turismo de temporada, férias ou finais de semanas SENA e Queiróz (2006).

De modo geral, trata-se de uma atividade onerosa para os destinos receptores em virtude da sobrecarga que acontece nessas localidades. Na maioria das vezes essa sobrecarga tem muito a ver com trânsito caótico, elevação nos preços do comércio local, saturação dos principais equipamentos de lazer e entretenimento, a exemplo de filas em restaurantes, problemas no fornecimento de água potável, poluição do ar pelo excesso de veículos nas ruas, animais trazidos e abandonados, saturação dos serviços de saúde, com saturação total dos atrativos naturais Larrabure (2009).

Apesar da sua histórica e intensa expansão em escala mundial, a segunda residência ainda é um fenômeno pouco estudado e conhecido, necessitando de reflexões teóricas e estudos empíricos das suas mais diversas repercussões socioambientais, nas mais variadas regiões ao redor do mundo.

Pesquisas nessa área são necessárias para apontar os riscos e benefícios provenientes da disseminação desse segmento turístico, como também apontar possibilidades de reversão nas regiões onde isso ocorre sem planejamento.

A partir desse pressuposto, é muito salutar questionar sobre o que se pode acarretar em termos de transtornos para uma localidade que não possua infraestrutura adequada, através de um planejamento prévio para o desenvolvimento da atividade turística de segunda residência.

Nesse sentido, como sugere Almeida (2008), os impactos negativos do turismo de segunda residência em muitas localidades são muito maiores do que os benefícios que ele proporciona em épocas de temporada de férias, finais de semana ou feriados prolongados.

Além disso, se em alguma dessas temporadas algo não correr bem, seja por mau tempo, ou problemas econômicos, e até mesmo, problemas por falta de infraestrutura básica, como por exemplo, saneamento (ausência de água, esgoto e coleta de resíduos) ou ainda, eletricidade (fornecimento insuficiente ou sobrecarga), um determinado local pode demorar anos para se reestabelecer. Esses problemas tendem a refletir diretamente em impactos ao ambiente.

Mencionar os possíveis impactos ao meio ambiente em relação às práticas turísticas de residência secundária é tratar da questão do impacto na paisagem local, no processo dinâmico do uso e ocupação da terra. Que, conforme aborda Rodrigues (1996), a mudança da paisagem resulta da interação dialética que se estabelece entre residentes/turistas e os elementos do ambiente do local.

Em se tratando dos impactos que ocorrem nos núcleos receptores, segundo Bacal (1999), existe uma preocupação quanto aos efeitos da implantação e do desenvolvimento do turismo, principalmente, quando se reconhece o potencial crescimento da localidade e que se movimentam investimentos dos setores hoteleiro, do transporte, dos equipamentos turísticos 
e de lazer, junto à propaganda maciça nos núcleos emissores ocorre como resposta a invasão de turistas, com aumento considerável da demanda que, na maioria das vezes não é acompanhada por um planejamento adequado das instalações para receber os visitantes e sequer pela população nativa.

É muito importante estar atento às transformações ocasionadas pela disseminação da segunda residência, também, para os benefícios que resultam dessa transformação:

\begin{abstract}
La residencia secundaria puede tener efectos ambientales beneficiosos para determinadas zonas. La reconstrucción o rehabilitación de vivendas abandonadas o en ruinas ha contribuido a la de sus núcleos tradicionales. Incluso, otros edificios en ruina o en desuso como antiguos establos han sido transformados en residencias secundarias. En determinadas zonas, cuando las remodelaciones conservan la armonía arquitectónica preexistente, este tipo de vivenda ha permitido salvaguardar el patrimonio inmobiliario (COLÁS, 2003, p. 65).
\end{abstract}

Apesar dessa perspectiva, geralmente, o turismo de segunda residência contribui com as crescentes urbanizações desordenadas e expansão turística, principalmente nas regiões costeiras, acarretando em mudanças significativas tanto na paisagem quanto nos ecossistemas. Em contrapartida, alguns setores como por exemplo o comércio local se beneficia com o incremento das receitas advindas da demanda turística sazonal, tendo em vista que alguns deles, dependem significativamente do período da temporada de férias para aumentar a renda familiar. Algo que deve ser levado em consideração, frente aos demais impactos estudados a exemplo do meio ambiente.

O balneário Ipanema, no município de Pontal do Paraná, no litoral do estado do Paraná, visualmente apresenta inúmeros conflitos socioambientais decorrentes do desenvolvimento rápido e espontâneo do turismo de segunda residência, se observarmos sua recente emancipação, a partir do ano de 1995.

Para Pereira (2013) um lugar só é bom para o turista se for bom para quem mora nele. Nessa perspectiva, as discussões sobre o tema, foram conduzidas no presente texto, seguindo a potencialidade turística do local, com a devida qualidade de vida e ambiental da comunidade local.

Diante deste contexto, o trabalho teve como objetivo geral, evidenciar o aumento do consumo gerado pelo turismo de segunda residência no balneário Ipanema, no litoral do estado Paraná.

\title{
3. METODOLOGIA
}

O presente trabalho foi executado com base em uma pesquisa exploratória através do desenvolvimento de uma projeção plana referente ao traçado do uso do solo no balneário Ipanema elaborado através de conhecimento prévio, da observação direta, no local de estudo. A estrutura metodológica de otimização deste trabalho foi composta pelas seguintes etapas: Etapa 1: Análise da literatura focando nas seguintes áreas: turismo sustentável, segunda residência e sazonalidade, indicadores e principais impactos transformadores da paisagem e do meio ambiente; 
Etapa 2: Levantamento da distribuição do uso do solo para fins de residência permanente e ocasional, assim como para fins de comércio permanente e ocasional, conforme o IBGE (2010a);

Etapa 3: Projeção de um croqui com a ocupação do solo, demarcando e quantificando os lotes em residenciais permanentes e ocasionais, comerciais permanentes e ocasionais, realizado através do software Google Earth;

Etapa 4: O estabelecimento dos critérios e seus respectivos parâmetros que norteiem a discussão dos problemas ambientais em decorrência do turismo sazonal e ou de segunda residência;

Etapa 5: Apresentação quantitativa, por meio de cálculos, tabelas e porcentagens dos resultados alcançados;

Etapa 6: Inferência dos potenciais problemas ambientais decorrentes da sazonalidade do turismo no balneário Ipanema.

\section{RESULTADOS}

De acordo com o Censo IBGE (2010b), o balneário Ipanema possui o quantitativo total de 3.488 domicílios, destes 2.513 são de uso ocasional e ou temporada de férias, enquanto que 975 são de uso permanente, isto é, possuem ocupação o ano inteiro.

No entanto, após a pesquisa de campo, através do levantamento e distribuição do uso e ocupação do solo, da confecção do croqui do balneário Ipanema, chegou-se à informação quantitativa de um total de 3.828 domicílios. Acarretando em 340 domicílios a mais que o informado pelo censo. Essa diferença possivelmente é decorrente da diferença metodológica utilizada na coleta de dados, afinal o IBGE costuma acessar as residências e realizar entrevista com os moradores, obtendo assim, maior número de informações expostas pelos entrevistados, enquanto que na pesquisa de campo, o pesquisador apenas observou do lado de fora, quantificando os lotes residenciais e comerciais abertos, com residentes e ou permanentes e fechados, sem residente ou de uso ocasional.

Por meio da visualização in loco, constatou-se que do total de 3.823 domicílios, 805 estão ocupados permanentemente, enquanto que 3.023 são de uso ocasional ou de temporadas.

Além disso, a pesquisa de campo contabilizou a existência de 211 estabelecimentos comerciais totais diversos, sendo 107 permanentes, ou seja, em funcionamento o ano todo e 104 ocasionais ou que funcionam apenas em feriados ou temporada de férias.

A distribuição do uso do solo entre comercial e residencial permanentes e ocasionais no balneário Ipanema é apresentada nas figuras 1 e 2. 


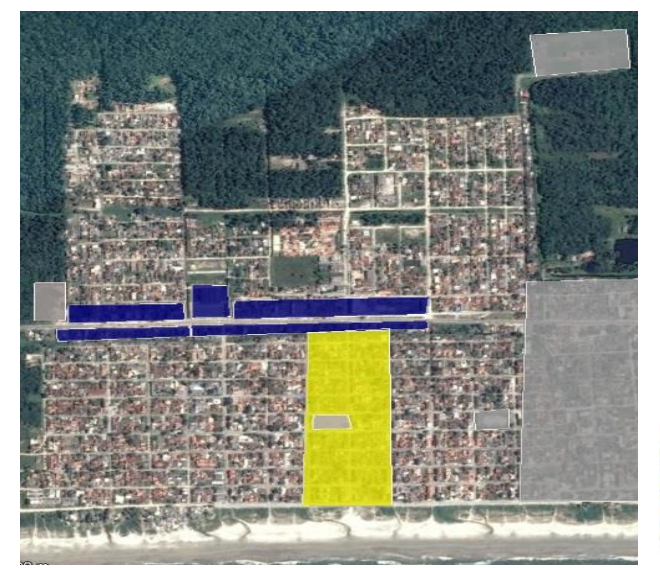

Legenda:

Comércios Ocasionais

Comércios Permanentes

Outros

Figura 1: Croqui com a representação de contexto da distribuição do comércio permanente e ocasional do balneário Ipanema.

Fonte: os autores, 2017.

Na figura 1 observa-se que o comércio permanente em número de 107 estabelecimentos diversos está estabelecido principalmente às margens da PR 412, que é a principal via de acesso ao balneário, em ambos os lados e concomitantemente a isso, situa-se mais próximo da área de domicílios permanentes. Desse modo, facilita a movimentação econômica do comércio local, que é a principal fonte de receita do balneário. Enquanto que, o comércio ocasional está localizado às margens da Rua São Luiz, conhecida popularmente como o calçadão de Ipanema. Vale salientar que a rua onde está o comércio ocasional localiza-se a leste da rodovia PR 412, e portanto mais próxima da região onde concentram-se os domicílios ocasionais e o principal atrativo de lazer e entretenimento, a praia. Isso explica, pelo fato de que na temporada de férias e feriados prolongados a região concentra um alto número de visitantes ocupando as residências na proximidade desse tipo de comércio. Pois comumente, ele só funciona em períodos sazonais.

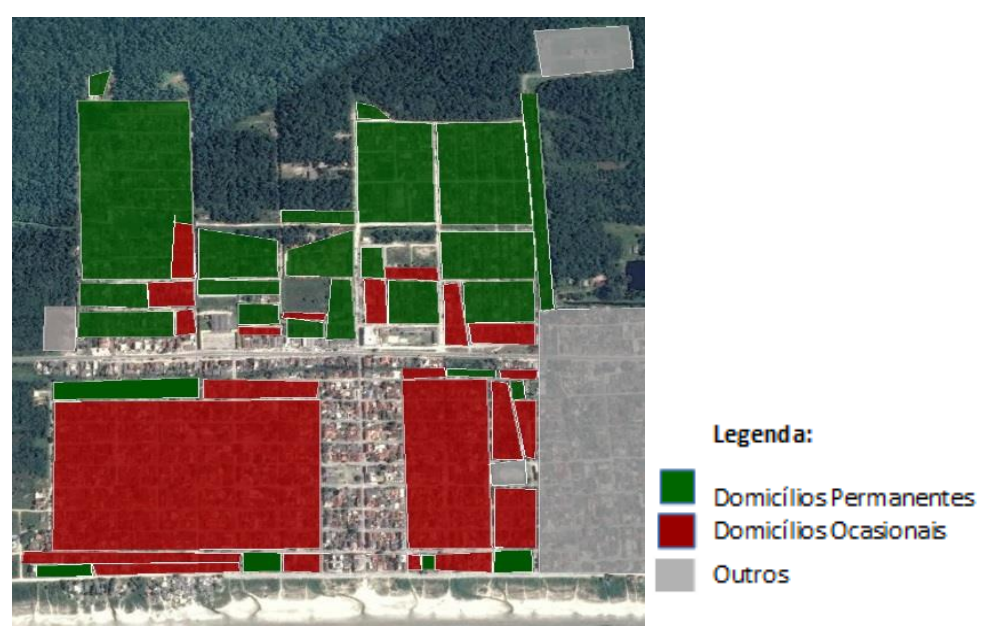

Figura 2: Croqui com a representação de contexto da distribuição residencial permanente e ocasional do balneário Ipanema.

Fonte: os autores, 2017. 
$\mathrm{Na}$ figura 2 temos a distribuição das residências, estando as permanentes fixadas principalmente na faixa oeste do balneário e posterior a rodovia PR 412, no sentido da vegetação. $O$ que explicaria esse fenômeno é o fato de que nessa região o valor de mercado dos lotes e residências tendem a ser mais baratos, haja vista que se trata de uma região com menos infraestrutura básica de serviços públicos. No entanto, é possível observar que algumas dessas residências também estão intercaladas junto às residências ocasionais, na faixa leste do balneário, mas em número significativamente reduzido, talvez por pessoas que detenham um poder aquisitivo mais elevado. Nota-se que quanto mais próximo do mar é que está a maior quantidade dos domicílios ocasionais e ou de temporada de férias. Afinal, é comum que o turista de segunda residência possua condição financeira melhor, no sentido de que possa arcar com os custos de uma segunda

residência. Além disso, se trata de imóveis com valor de mercado mais elevado, tendo em vista estarem situados próximo ao mar e a região possuir uma infraestrutura de serviços mais completa.

Essa distribuição diferenciada tanto das residências quanto do comércio ocasional é uma informação relevante para gestão pública planejar o uso do solo na temporada e fora dela. Podendo direcionar e concentrar ações em função dessa diferença na distribuição do comércio e dos domicílios, no sentido de tentar minimizar os potenciais impactos ambientais decorrentes do consumo diferenciado, constatado, como segue na apresentação dos resultados.

Para a presente pesquisa estipulou-se o período de 4 meses para a temporada, levando-se em conta os 3 meses do verão mais os feriados prolongados, assim como os finais de semana que são comuns ao turismo de segunda residência.

No que se refere à demanda, a tabela 1 apresenta os resultados referentes ao consumo de energia elétrica com base nos dados do levantamento de campo para os domicílios permanentes e ocasionais, para a temporada e demais meses do ano.

A tabela 1 mostra que, no balneário o consumo de energia elétrica aumenta significativamente se considerarmos o uso residencial ocasional durante a temporada, que representa $79 \%$ do total consumido na temporada. Evidenciando, desta forma, um significativo aumento no consumo de energia nesse período.

Se considerarmos questões ambientais sazonais como o aumento de temperatura e fotoperiodismo, essa estimativa realizada pela média de consumo anual, está subestimada. Isto significa que o aumento do consumo é mais concentrado nos meses da temporada, em função do uso de mais aparelhos elétricos por mais tempo, para garantir o conforto térmico, como o uso de ar condicionador, para os residentes ocasionais e permanentes. 
Tabela 1: Consumo estimado de energia elétrica para os domicílios permanentes e ocasionais, no balneário Ipanema

\begin{tabular}{ccccccc}
\hline & \multicolumn{2}{c}{ Consumo/porcentagem - fora de temporada } & \multicolumn{2}{c}{ Consumo/porcentagem - temporada } \\
\hline Demicílios & $\begin{array}{c}\text { Domicílios } \\
\text { Ocasionais }\end{array}$ & $\begin{array}{c}\text { Consumo } \\
\text { total } \\
\text { Permanentes } \\
\text { /Ocasionais }\end{array}$ & $\begin{array}{c}\text { Domicílios } \\
\text { Permanentes }\end{array}$ & $\begin{array}{c}\text { Consumo } \\
\text { Domicílios } \\
\text { Ocasionais }\end{array}$ & $\begin{array}{c}\text { Total } \\
\text { Permanentes/ } \\
\text { Ocasionais }\end{array}$ \\
\hline $\begin{array}{c}\text { Número } \\
\text { de }\end{array}$ & 805 & 3.023 & 3.828 & 805 & 3.023 & 3.828 \\
Domicílios & $(21 \%)$ & $(79 \%)$ & $(21 \%)$ & $(21 \%)$ & $(79 \%)$ & $(100 \%)$ \\
\hline Kwh/\% & 1.535 .940 & 0 & 1.535 .940 & 511.980 & 1.922 .628 & 2.434 .608 \\
& $(44,4 \%)$ & 0 & $(44,4 \%)$ & $(21, \%)$ & $(79 \%)$ & $(100 \%)$ \\
\hline
\end{tabular}

Fonte: Pesquisa de Campo realizada por Lucivan Macena de Carvalho, 2017.

Obs.: O parâmetro para os números acima foi de 159 Kwh mensal por domicílio, de acordo com dados da Empresa de pesquisa energética - EPE, 2017.

Nota-se que, no consumo de energia elétrica a elevação é evidente na alta temporada, indicando que o número de pessoas presentes no balneário e/ou de residências ocupadas é muito maior nesse período. Essa variação no consumo de energia elétrica indica que a dinâmica do balneário muda e consequentemente deve mudar os impactos ambientais gerados no local. Afinal, o consumo das residências ocasionais é praticamente zero fora de temporada.

Em relação ao indicador, consumo de água, os resultados foram obtidos de acordo com a estimativa de consumo no Brasil realizada pela ABES - Agência brasileira de engenharia sanitária (2017), tem-se assim como referência uma média de 150 litros por indivíduo/dia, o que acarreta em $18 \mathrm{~m}^{3}$ por mês em um domicílio com 4 pessoas. A tabela 2 mostra que em relação aos dados do trabalho de campo, o consumo dos domicílios permanentes são responsáveis por $57.960 \mathrm{~m}^{3}$ do consumo de água na temporada, enquanto que os ocasionais imprimem um consumo de $79 \%$ maior. O que equivale a dizer que na temporada o consumo de água potável aumenta $217.656 \mathrm{~m}^{3}$.

Tabela 2: Consumo/porcentagem estimado de água com os domicílios permanentes e ocasionais no balneário Ipanema

\begin{tabular}{ccccccc}
\hline & \multicolumn{3}{c}{ Consumo/porcentagem - fora de temporada } & \multicolumn{2}{c}{ Consumo/porcentagem - temporada } \\
\hline & $\begin{array}{c}\text { Domicílios } \\
\text { Permanentes }\end{array}$ & $\begin{array}{c}\text { Domicílios } \\
\text { Ocasionais } \\
-\end{array}$ & $\begin{array}{c}\text { Consumo } \\
\text { total } \\
\text { Permanentes } \\
\text { /Ocasionais }\end{array}$ & $\begin{array}{c}\text { Domicílios } \\
\text { Permanentes }\end{array}$ & $\begin{array}{c}\text { Domicílios } \\
\text { Ocasionais }\end{array}$ & $\begin{array}{c}\text { Consumo } \\
\text { Total } \\
\text { Permanentes/ } \\
\text { Ocasionais }\end{array}$ \\
\hline $\begin{array}{c}\text { Número } \\
\text { de }\end{array}$ & 805 & 3.023 & 3.828 & 805 & 3.023 & 3.828 \\
Domicílios & $(21 \%)$ & $(79 \%)$ & $(100 \%)$ & $(21 \%)$ & $(79 \%)$ & $(100 \%)$ \\
\hline M3/\% & 173.880 & 0 & 173.880 & 57.960 & 217.656 & 275.616 \\
& $(44,4 \%)$ & 0 & $(44,4 \%)$ & $(21, \%)$ & $(79 \%)$ & $(100 \%)$ \\
\hline
\end{tabular}

Fonte: Pesquisa de Campo realizada por Lucivan Macena de Carvalho, 2017.

Obs.: O parâmetro para os números acima foi de $18 \mathrm{M}^{3}$ mensal por domicílio, de acordo com informações da Agência brasileira de engenharia sanitária, 2017. 
Infere-se, desta forma que o impacto ambiental na temporada é maior considerando as implicações da maior demanda por água potável e posterior geração de esgoto sanitário. Levando-se em conta que fora da temporada os domicílios ocasionais representam o mínimo consumo de água, pois permanecem fechados a maior parte do ano. Assim como também, existe maior produção de efluentes domésticos, destacados na tabela 3, a seguir.

Tabela 3: Produção estimada de efluentes pelos domicílios permanentes e ocasionais no balneário Ipanema

\begin{tabular}{ccccccc}
\hline & \multicolumn{2}{c}{ Produção/porcentagem - fora de temporada } & \multicolumn{2}{c}{ Produção/porcentagem - temporada } \\
\hline & $\begin{array}{c}\text { Domicílios } \\
\text { Permanentes }\end{array}$ & $\begin{array}{c}\text { Domicílios } \\
\text { Ocasionais }\end{array}$ & $\begin{array}{c}\text { Consumo } \\
\text { total } \\
\text { Permanentes } \\
\text { /Ocasionais }\end{array}$ & $\begin{array}{c}\text { Domicílios } \\
\text { Permanentes }\end{array}$ & $\begin{array}{c}\text { Domicílios } \\
\text { Ocasionais }\end{array}$ & $\begin{array}{c}\text { Consumo } \\
\text { Total } \\
\text { Permanentes/ } \\
\text { Ocasionais }\end{array}$ \\
\hline $\begin{array}{c}\text { Número } \\
\text { de }\end{array}$ & 805 & 3.023 & 3.828 & 805 & 3.023 & 3.828 \\
Domicílios & $(21 \%)$ & $(79 \%)$ & $(100 \%)$ & $(21 \%)$ & $(79 \%)$ & $(100 \%)$ \\
\hline M3\% & 173.880 & 0 & 173.880 & 57.960 & 217.656 & 275.616 \\
& $(44,4 \%)$ & 0 & $(44,4 \%)$ & $(21, \%)$ & $(79 \%)$ & $(100 \%)$ \\
\hline
\end{tabular}

Fonte: Pesquisa de Campo realizada por Lucivan Macena de Carvalho, 2017.

Obs.: O parâmetro para os números acima foi de $18 \mathrm{M}^{3}$ mensal por domicílio, conforme dados da Agência estadual de meio ambiente de Pernambuco - CPRH.

Os resultados para a produção de efluentes domésticos, seguiu o parâmetro estimado pela $\mathrm{CPRH}$, Agência Estadual de Meio Ambiente do Estado de Pernambuco, para um domicílio com até 4 pessoas. De acordo com este parâmetro um domicílio, unifamiliar com média de quatro pessoas conforme citado, produz um total de 600 litros por dia de efluentes domésticos na rede coletora de esgoto, o que equivale à média de 18.000 Litros ou $18 \mathrm{~m}^{3}$ por mês na rede.

A tabela 3 mostra que os domicílios ocasionais são responsáveis por $79 \%$ do total da produção de efluentes durante a temporada, enquanto que os domicílios permanentes representam $21 \%$ da produção de esgoto. Isso equivale a um acréscimo de $54.414 \mathrm{~m}^{3}$ por mês na temporada. Ressalta-se que o impacto é o mínimo fora da temporada em virtude dessas residências estarem fechadas e não produzirem esgotos.

No que se refere à produção de resíduos sólidos os resultados obtidos se deram através das estimativas da ABRELPE 2015, cuja a produção no Paraná, por habitante ao dia de resíduos sólidos, foi de $0,748 \mathrm{~kg}$, o que dá $2,9 \mathrm{~kg} /$ dia em uma residência com 4 pessoas e um total de 1,04 toneladas por ano.

Desta forma, vemos na tabela 4 que os domicílios permanentes geraram na temporada um total de $280.140 \mathrm{~kg}$, ou seja, $70.035 \mathrm{~kg}$ por mês, à medida que os ocasionais representam $1.052 .004 \mathrm{~kg}$ dos resíduos do total de resíduos sólidos gerados, ou $263.001 \mathrm{~kg}$ ao mês. Isto representa um aumento $192.966 \mathrm{~kg}$ por mês na geração de resíduos sólidos no período da temporada. 
Tabela 4: Produção estimada de resíduos sólidos por domicílios permanentes e ocasionais no balneário Ipanema

\begin{tabular}{|c|c|c|c|c|c|c|}
\hline & \multicolumn{3}{|c|}{ Produção/porcentagem - fora de temporada } & \multicolumn{3}{|c|}{ Produção/porcentagem - temporada } \\
\hline & $\begin{array}{l}\text { Domicílios } \\
\text { Permanentes }\end{array}$ & $\begin{array}{c}\text { Domicílios } \\
\text { Ocasionais } \\
\text { - }\end{array}$ & $\begin{array}{c}\begin{array}{c}\text { Consumo } \\
\text { total }\end{array} \\
\text { Permanentes } \\
\text { /Ocasionais }\end{array}$ & $\begin{array}{c}\text { Domicílios } \\
\text { Permanentes }\end{array}$ & $\begin{array}{l}\text { Domicílios } \\
\text { Ocasionais }\end{array}$ & $\begin{array}{c}\text { Consumo } \\
\text { Total } \\
\text { Permanentes/ } \\
\text { Ocasionais }\end{array}$ \\
\hline $\begin{array}{l}\text { Número } \\
\text { de }\end{array}$ & $\begin{array}{c}805 \\
(21 \%)\end{array}$ & $\begin{array}{l}3.023 \\
(79 \%)\end{array}$ & $\begin{array}{c}3.828 \\
(100 \%)\end{array}$ & $\begin{array}{c}805 \\
(21 \%)\end{array}$ & $\begin{array}{l}3.023 \\
(79 \%)\end{array}$ & $\begin{array}{c}3.828 \\
(100 \%)\end{array}$ \\
\hline Domicílios & & & & & & \\
\hline $\mathrm{Kg} / \%$ & $\begin{array}{l}840,420 \\
(44,4 \%)\end{array}$ & $\begin{array}{l}0 \\
0\end{array}$ & $\begin{array}{l}840,420 \\
(44,4 \%)\end{array}$ & $\begin{array}{c}280.140 \\
(21, \%)\end{array}$ & $\begin{array}{c}1.052 .004 \\
(79 \%)\end{array}$ & $\begin{array}{c}1.332 .144 \\
(100 \%)\end{array}$ \\
\hline
\end{tabular}

Fonte: Pesquisa de Campo realizada por Lucivan Macena de Carvalho, 2017.

Obs.: O parâmetro para os números acima foi de $87 \mathrm{~kg}$ mensal por domicílio, de acordo com informações da Associação Brasileira de Empresas de Limpeza Pública e Resíduos Especiais - ABRELPE, 2015.

O aterro utilizado, ao qual os resíduos são destinados, atende o município de Matinhos e Pontal do Paraná, e o mesmo já se encontra com a capacidade esgotada e sem qualquer tipo de tratamento adequado. Tal situação se transforma em mais um problema ambiental tornando-se uma fonte de poluição.

Em relação aos números do setor comercial, e os seus resultados, segundo a fonte IPARDES,(2016), Instituto Paranaense de Desenvolvimento Econômico e social, o total de estabelecimentos comerciais em todo o município de Pontal do Paraná é de 1.362 unidades, consumindo em 2016 um total de $12.123 \mathrm{Mwh}$, o mesmo que dizer que cada unidade consome mensalmente um total de $741,6 \mathrm{Kwh}$ em média. No entanto, para finalidade dos resultados apresentados, os números utilizados foram as informações da pesquisa de campo que contabilizou um total de 211 estabelecimentos diversos no balneário Ipanema, destes, 107 são considerados comércios permanentes e 104 ocasionais ou de temporadas.

No que se refere ao consumo energético por estabelecimento comercial, a tabela 5 mostra que, no balneário o consumo de energia elétrica aumenta praticamente $50 \%$ se considerarmos - funcionamento dos estabelecimentos comerciais ocasionais durante a temporada. Evidenciando, desta forma, um significativo aumento no consumo de energia na temporada. 
Tabela 5: Consumo estimado de energia elétrica para a temporada para os estabelecimentos comerciais permanentes e ocasionais, no balneário Ipanema

\begin{tabular}{ccccccc}
\hline & \multicolumn{1}{c}{ Produção/porcentagem - fora de temporada } & \multicolumn{2}{c}{ Produção/porcentagem - temporada } \\
\hline Comércio & Comércio & $\begin{array}{c}\text { Consumo } \\
\text { total } \\
\text { Ocasional }\end{array}$ & $\begin{array}{c}\text { Comércio } \\
\text { Permanente/ } \\
\text { Ocasional }\end{array}$ & $\begin{array}{c}\text { Comércio } \\
\text { Permanente } \\
\text { Ocasional }\end{array}$ & $\begin{array}{c}\text { Consumo } \\
\text { Total } \\
\text { Permanente/ } \\
\text { Ocasional }\end{array}$ \\
\hline $\begin{array}{c}\text { Número } \\
\text { de }\end{array}$ & 107 & 104 & 211 & 107 & 104 & 211 \\
comércios & $(50,8 \%)$ & $(49,2 \%)$ & $(100 \%)$ & $(50,8 \%)$ & $(49,2 \%)$ & $(100 \%)$ \\
\hline KWh/\% & 952.214 .4 & 0 & 952.214 .4 & 317.404 .8 & 308.506 .6 & 625.911 .4 \\
& $(75,5 \%)$ & 0 & $(75,5 \%)$ & $(50,7, \%)$ & $(49,3 \%)$ & $(100 \%)$ \\
\hline
\end{tabular}

Fonte: IPARDES (2017).

Obs.: O parâmetro para os números acima foi de 741,6 Kwh/mês por estabelecimento comercial, de acordo com dados do IPARDES (2016).

Para o consumo de água por estabelecimentos comerciais a FECOMERCIO-SP 2017, Federação do comércio do Estado de São Paulo, estipula o total de 600 litros por mês para cada unidade, dessa forma, a tabela 6 mostra que em virtude da quantidade de estabelecimentos serem praticamente iguais em relação a permanentes e ocasionais, o acréscimo no consumo também ficou em aproximadamente $50 \%$ a mais na temporada, sendo $50,8 \%$ e $49,2 \%$ respectivamente.

Tabela 6: Consumo/porcentagem estimado de água pelo comércio permanente e ocasional no balneário Ipanema

\begin{tabular}{ccccccc}
\hline & \multicolumn{2}{c}{ Produção/porcentagem - fora de temporada } & \multicolumn{2}{c}{ Produção/porcentagem - temporada } \\
\hline Comércios & $\begin{array}{c}\text { Comércios } \\
\text { Ocasionais } \\
\text { Permanentes }\end{array}$ & $\begin{array}{c}\text { Consumo } \\
\text { total } \\
\text { Permanentes } \\
\text { /Ocasionais }\end{array}$ & $\begin{array}{c}\text { Comércios } \\
\text { Permanentes }\end{array}$ & $\begin{array}{c}\text { Comércios } \\
\text { Ocasionais }\end{array}$ & $\begin{array}{c}\text { Consumo } \\
\text { Total } \\
\text { Permanentes/ } \\
\text { Ocasionais }\end{array}$ \\
\hline $\begin{array}{c}\text { Número } \\
\text { de }\end{array}$ & 107 & 104 & 211 & 107 & 104 & 211 \\
comércios & $(50,8 \%)$ & $(49,2 \%)$ & $(100 \%)$ & $(50,8 \%)$ & $(49,2 \%)$ & $(100 \%)$ \\
\hline Litros/\% & 770.400 & 0 & 770.400 & 256.800 & 249.600 & 506.400 \\
& $(75,6 \%)$ & 0 & $(75,6 \%)$ & $(50,8 \%)$ & $(49,2 \%)$ & $(100 \%)$ \\
\hline
\end{tabular}

Fonte: Pesquisa de Campo realizada por Lucivan Macena de Carvalho, 2017.

Obs.: O parâmetro para os números acima foi de $600 \mathrm{~L}$ mensal por unidade comercial, com base nos dados da FECOMERCIO-SP (2017).

Em relação ao setor comercial a média dos principais estabelecimentos presentes no balneário Ipanema produz cerca de 75 litros por dia de efluentes na rede coletora, de acordo com as projeções da CPRH. Sendo assim, o setor comercial em estudo é responsável por produzir em média 2.250 litros por mês de efluentes, a tabela 7 mostra que a carga no sistema de esgotamento ficou aproximadamente $50 \%$ a mais durante a temporada de férias, o que equivale dizer que os estabelecimentos permanentes e ocasionais impactam na mesma proporção com $50,8 \%$ e $49,2 \%$ respectivamente. Se compararmos a média anual para esseo parâmetro, observaremos que o comércio ocasional representa apenas $24,4 \%$ do total, enquanto que o comércio permanente, ou seja, que funciona o ano inteiro, é responsável por $75,6 \%$ do efluente produzido, uma variação de $51.2 \%$ a mais. 
Tabela 7: Produção estimada de efluentes pelo comércio permanente e ocasional no balneário Ipanema

\begin{tabular}{|c|c|c|c|c|c|c|}
\hline & \multicolumn{3}{|c|}{ Produção/porcentagem - fora de temporada } & \multicolumn{3}{|c|}{ Produção/porcentagem - temporada } \\
\hline & $\begin{array}{c}\text { Comércios } \\
\text { Permanentes }\end{array}$ & $\begin{array}{c}\text { Comércios } \\
\text { Ocasionais } \\
-\end{array}$ & $\begin{array}{c}\text { Consumo } \\
\text { total }\end{array}$ & $\begin{array}{c}\text { Comércios } \\
\text { Permanentes }\end{array}$ & $\begin{array}{l}\text { Comércios } \\
\text { Ocasionais }\end{array}$ & $\begin{array}{c}\text { Consumo } \\
\text { Total } \\
\text { Permanentes/ } \\
\text { Ocasionais }\end{array}$ \\
\hline $\begin{array}{l}\text { Número } \\
\text { de }\end{array}$ & $\begin{array}{c}107 \\
(50,8 \%)\end{array}$ & $\begin{array}{c}104 \\
(49,2 \%)\end{array}$ & $\begin{array}{c}211 \\
(100 \%)\end{array}$ & $\begin{array}{c}107 \\
(50,8 \%)\end{array}$ & $\begin{array}{c}104 \\
(49,2 \%)\end{array}$ & $\begin{array}{c}211 \\
(100 \%)\end{array}$ \\
\hline Comércios & & & & & & \\
\hline Litros/\% & $\begin{array}{c}2.889 .000 \\
(75,6 \%)\end{array}$ & $\begin{array}{l}0 \\
0\end{array}$ & $\begin{array}{c}2.889 .000 \\
(75,6 \%)\end{array}$ & $\begin{array}{l}963.000 \\
(50,8 \%)\end{array}$ & $\begin{array}{l}936.000 \\
(49,2 \%)\end{array}$ & $\begin{array}{c}1.899 .000 \\
(100 \%)\end{array}$ \\
\hline
\end{tabular}

Fonte: Pesquisa de Campo realizada por Lucivan Macena de Carvalho, 2017.

Obs.: O parâmetro para os números acima foi de $2.250 \mathrm{~L}$ mensal por comércio, com base nos dados da CPRH.

Realizando-se a média de produção de efluentes dos principais tipos de estabelecimentos presentes no balneário Ipanema.

Por último, e tão importante quanto os demais indicadores levantados, está a questão da geração de resíduos sólidos por esses estabelecimentos comerciais. Conforme Domingues (2013), em sua proposta de um plano de gerenciamento de resíduos sólidos para estabelecimentos comerciais, foi possível estimar que estes, são responsáveis pela geração média de $2.155 \mathrm{~kg}$ por mês de resíduos. Desse modo, conforme mostra a tabela 8 , observamos que durante a temporada o comércio ocasional impacta diretamente em $49,12 \%$ na produção dos resíduos sólidos, paralelo aos $50,88 \%$ do comércio permanente, o que se conclui que praticamente dobra a carga de resíduos.

Tabela 8: Produção/porcentagem estimado de resíduos sólidos pelo comércio permanente e ocasional no balneário Ipanema

\begin{tabular}{ccccccc}
\hline & \multicolumn{2}{c}{ Produção/porcentagem - fora de temporada } & \multicolumn{2}{c}{ Produção/porcentagem - Temporada } \\
\hline & $\begin{array}{c}\text { Comércios } \\
\text { Permanente } \\
\mathbf{s}\end{array}$ & $\begin{array}{c}\text { Comércios } \\
\text { Ocasionais - }\end{array}$ & $\begin{array}{c}\text { Consumo } \\
\text { total } \\
\text { Permanentes/ } \\
\text { Ocasionais }\end{array}$ & $\begin{array}{c}\text { Comércios } \\
\text { Permanentes }\end{array}$ & $\begin{array}{c}\text { Comércios } \\
\text { Ocasionais }\end{array}$ & $\begin{array}{c}\text { Consumo } \\
\text { Total } \\
\text { Permanentes/ } \\
\text { Ocasionais }\end{array}$ \\
\hline $\begin{array}{c}\text { Número } \\
\text { de }\end{array}$ & 107 & 104 & 211 & 107 & 104 & 211 \\
Comércios & $(50,8 \%)$ & $(49,2 \%)$ & $(100 \%)$ & $(50,8 \%)$ & $(49,2 \%)$ & $(100 \%)$ \\
\hline $\mathrm{Kg} / \%$ & 2.767 .020 & 0 & 2.767 .020 & 922.340 & 890.480 & 1.812 .820 \\
& $(75,7 \%)$ & 0 & $(75,7 \%)$ & $(50,88 \%)$ & $(49,12 \%)$ & $(100 \%)$ \\
\hline
\end{tabular}

Fonte: Pesquisa de Campo realizada por Lucivan Macena de Carvalho, 2017.

Obs.: O parâmetro para os números acima foi de $2.155 \mathrm{Kg}$ mensal por comércio, com base em Domingues (2013).

Dessa forma, percebemos por meio dos resultados obtidos, mostrado pelos indicadores pesquisados, que existe um acréscimo significativo no consumo dos serviços pesquisados. Há possíveis impactos gerados sazonalmente como consequência do aumento da demanda dos serviços mostrados pelos resultados obtidos. Essa sobrecarga influencia diretamente na qualidade de vida dos moradores do balneário Ipanema, afinal são estes que sofrem no momento que aumenta substancialmente a demanda de serviços mostrados como indicadores de consumo. 


\section{CONCLUSÃO}

Utilizando-se a observação prévia, pesquisa de campo com a devida coleta de dados e análise dos resultados, observou-se que o balneário de Ipanema no município de Pontal do Paraná, localizado no litoral paranaense, de forma geral, funciona como uma região de segunda residência de turistas e famílias de diversas regiões do estado com a finalidade de lazer, que nada mais é do que um tipo de hospedagem associada à atividade turística de finais de semana, feriados e temporadas. O balneário é procurado e visitado principalmente por famílias que possuem algum tipo de imóvel no local, fazendo uso dos mesmos em períodos esporádicos.

Essa ocupação dos usos ocasionais não é aleatória, indicando uma segregação espacial entre os usos residencial permanente e ocasional e entre o uso comercial permanente e ocasional. Outros estudos que possam avaliar questões sociais e econômicas são necessárias para subsidiar a gestão pública com medidas para a redução das desigualdades espaciais no planejamento urbano municipal.

Os resultados apresentados corroboraram na indicação de sobrecarga dos serviços básicos de infraestrutura, atingindo principalmente a população fixa do município, essa sobrecarga ficou evidenciada e muitas vezes ultrapassou os $50 \%$ em relação aos moradores do balneário Ipanema. Ficou evidente a elevação do consumo sazonal e a potencial sobrecarga ambiental que sofre o balneário estudado, acarretando em transtornos para a população local. Tal evidência mostrou o aumento no consumo de energia elétrica, água, efluentes e resíduos sólidos na alta temporada. Assim, pode-se realizar a inferência dos impactos ambientais, com diferenciação espacial para os usos comercial e domiciliar, ocasionais e permanentes, com confirmação espacial e numérica, por meio do aumento do consumo na temporada, no balneário Ipanema no município de Pontal do Paraná.

Contudo, espera-se com a presente pesquisa, possa subsidiar debates sobre as vantagens e desvantagens de incentivo à atividade de turismo de segunda residência, observando se o destino possui ou não, vocação para o turismo e infraestrutura que a suporte e os meios de intervenção.

\section{REFERÊNCIAS BIBLIOGRÁFICAS}

ABRELPE. Associação Brasileira de Empresas de Limpeza Pública e Resíduos Especiais. Panorama do resíduos sólidos no Brasil 2015. Disponível em: <http://www.abrelpe.org.br/Panorama/panorama2015.pdf>. Acesso em: 15 Ago. 2017.

Agência estadual de meio ambiente e recursos hídricos de Pernambuco (CPRH). Estimativas do volume de efluentes domésticos por fonte/pessoa/dia. Disponível em: <http://www.cprh.pe.gov.br/downloads/tabela1.pdf>. Acesso em: 17 Mai. 2017. 
ALMEIDA, A. L. de; KASTENHOLZ E. A sazonalidade no turismo e a estratégia de diversificação da procura: 0 Caso do Norte de Portugal. Conceptual Paper, 2ㅇ Encontro Luso-Brasileiro de Estratégia, ELBE: Lisboa, Portugal 2008.

ASSIS, L. F. Turismo de segunda residência: a expressão espacial do fenômeno e as possibilidades de análise geográfica. Revista Território. Ano VII, n. 11, 12 e 13 - set./out. 2003.

Associação Brasileira de Engenharia Sanitária (ABES). Consumo de água por habitante no Brasil é estável. Disponível em: <http://www.abes-mg.org.br/visualizacao-declippings/ler/2154/consumo-de-agua-por-habitante-no-brasil-e-estavel>. Acesso em: 16 Maio 2017.

BACAL, S. S., MIRANDA, S. M. de A. Impacto do turismo nos núcleos receptores: necessidades de normatização. In: RODRIGUES, A. B. (Org.). Turismo e desenvolvimento local. 2. ed. São Paulo: Hucitec, 1999. cap.6.

COLÁS, Julián Lópes. La residencia secundaria en España: estúdio territorial de uso y tenencia. Barcelona, 2003. p. 65. Tese (Doutorado em Geografia). Facultat de Filosofia i Lletres. Universitat Autônoma de Barcelona.

DOMINGUES, A. C. R. Proposta de Plano de gerenciamento de Resíduos sólidos (PGRS) para um restaurante no município de Campo Mourão - PR. Monografia (Monografia e Engenharia ambiental). UTFPR. Campo Mourão - PR. p. 31. 2013.

FECOMÉRCIO. Cartilha compara consumo de água por atividade e estabelecimentos. Disponível em: <www.fecomercio.com.br/noticia/cartilha-compara-consumo-de-agua-poratividades-e-estabelecimentos >. Acesso em: 15 Out. 2017.

IBGE. INSTITUTO BRASILEIRO DE GEOGRAFIA E ESTATÍSTICA. Histórico e População de Pontal do Paraná 2010a. Disponível em: $<$ http://cidades.ibge.gov.br/painel/historico. php?lang=\&codmun=411995\&search=parana $\mid$ po ntal-do-parana|infograficos:-historico>. Acesso em: 16 Fev. 2017.

INSTITUTO BRASILEIRO DE GEOGRAFIA E ESTATÍ́STICA. Censo demográfico 2010b. Disponível em: <http://cod.ibge.gov.br/2VTKB>. Acesso em: 23 Nov. 2017.

IPARDES. Caderno estatístico município de Pontal do Paraná. Disponível em: $<$ http://www.ipardes.gov.br/cadernos/MontaCadPdf1.php?Municipio=83255\&btOk=ok>.

Acesso em: 10 Out. 2017.

PEREIRA, Abgail. Um lugar só é bom para o turista se for bom para quem mora nele. Turismo Rio Grande do Sul, 2013. Disponível em: <http://www.rs.gov.br/conteudo/15460/artigo-umlugar-so-e-bom-para-o-turista-se-for-bom-para-quem-mora-nele-por-abgail pereiraLtermosbusca $=*$ >. Acesso em: 03 set. 2017.

LARRABURE, S. P. O fenômeno da segunda residência: o caso do Rio Grande entre os estados de São Paulo e Minas Gerais. GEOUSP - Espaço e Tempo. Edição Especial. 2009. 
RODRIGUES, A. B. (1996) - "Turismo e Território: a apreensão da dinâmica espacial", in. Rodrigues, A. B. (org), Turismo e Geografia. reflexões teóricas e enfoques regionais. São Paulo: HUCITEC, 1999. p. 81.

SENA, M. F. A.; QUEIROZ, O. T. M. M. Impactos ambientais e sócio-culturais do turismo de segunda residência: o caso de Ponta da Tulha, Ilhéus, BA. Caderno Virtual de Turismo. v. 6, $n^{\circ}$ 4, 2006. 